\title{
Communication Media And Supply Chain Management - Hypotheses Development
}

\author{
B. K. Purohit ${ }^{1}$, Dr. S. S. Hebbal ${ }^{2}$ \\ ${ }^{1}$ Research Scholar, C M J University, Shillong. (Meghalaya State) \\ ${ }^{2}$ Research Supervisor, Principal, P. D. A. College of Engineering Gulbarga. (Karnataka State)
}

\begin{abstract}
Effective communication between various tiers of supply chain management is an essential requirement in today's business. The traditional way of managing supply chains has changed almost over the last decade. Face-to-face management, manual tracking system, paper dominated order processing systems and various wired communication links (such as phone, fax) were the primary management tools. Today EDI, Email, Internet are in domination in providing fast accurate communication enhancing the supply chain performance. Further, though relational exchange and communication media are treated as independent phenomenon, there appears to be a close link between them. Good relationship requires effective communication. Thus the issue of whether High-Tech media foster coordination or competition has captured considerable attention by researchers.

This paper begins with reorganization of the importance of information systems within the management of supply chains and the impact information system can have on supply chain performance. In this article the authors have attempted to review the works of various researchers by the way of literature survey and there by develop the research hypotheses.
\end{abstract}

\section{INTRODUCTION}

Today the manufacturing companies are facing fierce competition from rival companies. The companies must continuously strive to upgrade and find new ways to compete to meet the business challenges. The competitive advantage is obtained by implementing effective supply chain management. With effective supply chain management the companies achieve $10 \%$ of revenue cost advantage, $20 \%$ higher order delivery performance and $50 \%$ less inventory in hand, as well as $66 \%$ quicker cash-to-cash cycle ( Productive News Nov-Dec, 2005).

The supply chain encompasses all the activities associated with the flow and transformation of goods from raw material stage through manufacturing, distribution to end users as well as associated information flow. Supply chain management is the integration of various activities through proper information flow and supply chain relationships to achieve sustainable competitive advantage.

In the present paper an attempt is made to study the impact of communication media on business in small and medium scale firms. Here an attempt is made to study two aspects of supply chain management. Firstly the use and effect of various communication media for accomplishing the supply chain activities of the firm and secondly, the effect of various communication media on relational exchange.

\section{OVERVIEW OF SCM}

Supply chain management consists of number of entities interacting with each other in complex ways. There is flow of material, fund and information across these entities. The flow of material, fund and information generates costs within the supply chain. The management of these flows is a key to the success [1].

Facilities, inventory, transportation and information are the key drivers of supply chain performance. Out of these drivers information serves as glue allowing other three drivers to work together for effectiveness of supply chain.

The supply chain management goals are multidimensional. The include cost minimization, increased level of services, improved communication among supply chain partners and increased flexibility in terms of delivery and response time. Till almost two decades the firms could not achieve above goals due to limitations of communication media and their cost. Further there was reluctance of small firms to provide certain confidential information to the partners with a threat of loosing competitive advantage.

Today there is change of attitude due to advancement in information technologies. Advanced communication media have brought supply chain partners closer and have improved the relationship among them.

This paper is the result of literature survey. The literature review has led to the development of research hypotheses. These hypotheses will be subject to testing in the next part of the research work. 


\section{LITERATURE REVIEW AND HYPOTHESES DEVELOPMENT}

\section{High-Tech and High-Touch media}

Many researchers have stated that, the information sharing plays key role in the management of supply chain. Effective communication is a critical component of buyer- supplier relationships. Purchasing professionals utilize a wide variety of communication media to communicate with suppliers. Variety of communication media are classified as high-touch and high-tech media either being synchronous or two way and asynchronous or one way [2]. Face to face (F2F) and telephone are high-touch synchronous media, the regular mail, fax are high-touch asynchronous media. On the other hand E-mail and electronic data interchange (EDI) are high-tech, asynchronous communication media. Further these media are categorized as rich and poor media. Richness or the poorness of a particular medium is based on number of clues that a communication medium possesses.

Electronic data interchange substitutes for more traditional forms of business communication such as mail, fax, telephone or face-to-face contact [3]. It is observed that the Internet and EDI can not supplant the need for direct interaction between the customer and supplier [4].

Paul D. Larson et al [5], in their research observed that half of the respondents in their survey report some degree of EDI and Internet deployment and less than $3 \%$ of their buyer supplier communication takes place electronically. Other said that, electronic media complement the use of phone and fax. Also many buyers prefer personal contact with their suppliers. Many buyers indicated that E-mail saves time and provides a valuable paper trail but too impersonal for real negotiation. They prefer close deals over phones.

Intelligent software agents can automate procurement process by communicating with suppliers via the Internet [6]. These agents visit suppliers, present requirements and even engage in negotiations. Though most purchasing professionals have Internet access, few actually use it [7].

Langel and Draft [8] categorizes the media. They observe that richness of medium should be matched to the needs of messages for effective communication. Face-to-face is the richest communication medium allowing multiple cues e.g. facial expression and body language, immediate feed back and personal focus. The telephone on the other hand is lower in richness because of fewer cues and less personal.

Mail and fax are less rich than phone due to further fewer cues and feed back is not immediate. Further electronic media such as EDI are impersonal and lowest in media richness. Langel and Draft [8] suggest that routine communication such as purchase orders do not require communication through rich media. But non routine communication is done via rich media. They further advice executives to use rich media for implementing company strategy.

The non routine communications are strategic. For such communications immediate feedback and two way interactions are important. Thus rich personal media such as face-to-face, telephone are most suitable for strategic communication. On the other hand tactical communication i.e. routine communication needs lesser two-way interaction. Thus electronic communication media such as EDI, E-mail and Internet are more useful for tactic communication such as purchase orders. Thus the first hypothesis is developed as below:

\section{Hypothesis 1: High-touch media are preferred for strategic communications and high-tech media for} tactical communications.

\section{Usage of advanced communication media}

The effective communication media may lower costs, increase information speed and reduce information errors which in turn may enable an effective and efficient product flow among the participants. These media would generally include advanced (high-tech) communication media.

Lee et al [9] pointed out that, the potential benefits of high-tech media are inconclusive. Even after more than 25 years of use of EDI in various industries the literature is still inconclusive regarding the benefits gained from its usage. But several studies have reported significant realization of benefits. There are varying levels of benefits reported from use of advanced communication media [10].

Craighead et al [10] observed that the variations in the benefits are high-tech media experience, supply chain infusion and implementation characteristics. Infusion is the degree to which the communication systems are implemented in the supply chain. If there are 100 suppliers in a manufacturing industry then the number of suppliers linked to the facility would be the measure of infusion. Thus as the infusion increases the benefits increase due to the increased use and reduced need of parallel systems. Within supply chain infusion there are three variables proportion of trading partners linked, proportion of transactions using communication media and proportion of total sales dollars converted to communication media.

Zillur Rahaman [11] conducted a study and reported that Internet will continue to provide fast and accurate information from a wide range of operating area including transportation, inventory, purchasing, customer service, production scheduling, order processing and vendor operations to improve profitability of the supply chain. 
High investments are needed to use advanced communication media which are known as IT investments. The IT investments include EDI, fax machine, PCs, software, training and support. It is not just important to make IT investments but it is important to make use of IT investments. Buyers strategically choose to utilize advanced communication media with key vendors or certain types of procurements such as high volume, recurrent orders. Not all suppliers are able or willing to incur the necessary implementation costs. When buyers understand to realize the substantial buying from their IT investments, it may be in their self interest to shoulder greater investments to subsidize their suppliers use. Thus the second research hypothesis is developed.

\section{Hypothesis 2: More the proportion of communication media usage more will be the benefits.}

\section{Communication media and lead time}

In the literature it has been shown that the use of advanced communication media has direct impact on cycle/lead time.

Richard A Lancioni et al [12] has established that the advanced communication medium such as Internet has affected all areas of operation from transportation and fleet management to the ways companies procure materials and process orders. The Internet allows automation of entire supply chain i.e. synchronization of demand, supply and production from raw material supplier to ultimate product consumer.

The Internet has the potential to accomplish a key goal of supply chain management, which is to cut cycle time, not in incremental steps but in broad swaths, by completely cutting down que time, move time and other aspects of cost and waste. Through Internet it is possible to fill up the purchase order forms, verify their credentials, complete secure transactions and receive confirmation trading partners. Even the product availability can be checked.

Juliet Webster [13] observed that advanced and high quality communication effects change in the competitive environment through reduced supplier base, JIT inventory management and quick response to customer demand. It facilitates faster ordering and receiving of materials than compared with paper based trading systems. Advanced communication is helpful in sharing information about markets, material requirements, forecasts, inventory levels and production and delivery schedules.

Handfield and Nicholas [14] argue that to participate in SCM initiatives it is required to reduce the cycle time. They out line the cause of poor cycle/lead time performance as lack of timely and accurate information and out dated information. Carter and Ragatz [15] report the expected benefits of EDI implementation include reduction in lead time and inventory.

Porter [16] reports improved supplier performance including shorter lead times and more on time deliveries among the benefits of EDI and other forms of purchasing automation. The above literature provides the base for following hypothesis.

Hypothesis 3: Lead time performance is improved by using high quality of information and advanced information technology.

\section{Communication media and SCM relationships}

The impact of communication media on relational exchange differs from small scale to large-scale enterprises. Many initiatives in supply chain management involve technological approach (e.g. electronic data interchange) or relational approach (e.g. supplier development). Barringer [17] developed a conceptual framework on relational exchange in the small supplier/large buyer context. This framework focuses on advantages and disadvantages for small suppliers, across dimensions of relational exchange, such as long-term orientation, mutual trust and open communication. Advantages of relational exchange include reduced transaction costs, more certain access to critical resources, reliable customer base and quality/cost improvements driven by buyer-supplier co-operation. Disadvantages for small supplier include loss of autonomy and flexibility, dependence on buyer, weaker negotiating position and having to share confidential cost and other information. These disadvantages are barriers to relational exchange between small suppliers and large buyers.

Lacking resources and managerial experience to capitalize on their innovative ideas, small firms see ideal candidates for their alliance relationships [18]. Alliances can offer them faster market penetration and financial risk sharing. Small firms face the risk of becoming dependent and lacking in powerful negotiating positions.

Small suppliers are concerned about dependence on buyers, along with possible negative effects of sharing their confidential information i.e. there are trust issues [19]. Buyer power over the small supplier leads to dominance and compliance rather than collaboration. More over, rather than to co-operate with any one of them larger buyers may prefer to keep small suppliers competing for shares of business.

There are mixed reactions over the impact of EDI on buyer-supplier relationships. Some researchers argue that EDI implementation can result in deteriorating relation ships [14]. Jairam et al [20] report no support for link between EDI and buyer-supplier partnering. Others have reported no relationship, since information 
technology programs are not designed to improve buyer-supplier relationships. Larson and Kulchitsky [2] report the absence of a significant link between EDI and inter organizational relations.

Many of the researchers have proposed a positive link between EDI and buyer-supplier relations. Emmethainz [21] reported EDI improves vendor relationships. Lender and Fearson [22] argue that EDI fosters closer buyer-supplier relationships. Similarly Sriram and Benerjee [23] claim that EDI brings buyer and suppliers closer to together. Thus there are contradictory reports regarding the EDI implementation and supply chain management relationships.

Similar study was also conducted by Paul D Larson et al [5] and they reported that buyer used greater relational exchange and electronic communication media with large suppliers compared to small suppliers. They further noted that though relational exchange and electronic communication media are usually treated as independent phenomenon, there appears to be a close link between them in supply chain management. Good relationships require effective communication. Thus electronic communication media such as EDI and Internet facilitates relational exchange between buyers and suppliers.

The issue of whether the Internet fosters coordination or competition has captured considerable attention from scholars. Some authors believe that competitive bidding makes the relationship with other supply chain members grow stronger [24].

Many researchers have reported that large buyers operate mixed communication systems, EDI with their large suppliers and traditional systems such as phone and fax with their small suppliers. Morgan [25] says that small suppliers feel that EDI gives big benefits for their large customers and cost for the small suppliers, themselves. Grossman [26] reports that large buyers often force their small suppliers to adopt newer information technology, without sharing the resulting benefits.

Hypothesis 4: High quality of information and increased use of advanced information technology will result in closer buyer-supplier relationship.

Hypothesis 5: Buyer will have more close and collaborative relationships with large suppliers than small suppliers.

Hypothesis 6: Lead-time performance is improved by closer buyer-supplier relationship.

\section{CONCLUSION}

The authors have attempted to review the works of various researchers and tried to consolidate the findings. Face-to-face (F2F) and telephone were strongly preferred for strategic communication. Phone and fax were strongly preferred for tactical communication and electronic media such as EDI, E-mail and Internet were characterized by low utilization.

The important electronic media EDI, E-mail and Internet are used more frequently with large suppliers compared to small suppliers. With the exception of E-mail, the electronic media are relatively under utilized to communicate with large and small suppliers alike phone, fax are more frequently used media for small and large suppliers. Buyers report significantly greater frequency of face - to-face communication with their large suppliers compared to their small suppliers because the buyers have closer, more collaborative relationships with their large suppliers.

The firms face threat of not competing in the business by sharing some of the sensitive information to the partners. Hence there is some reluctance to the use of electronic media. Some information may always need to be hidden from competitors. This fear is greatest among small companies.

A case study of Ford motor company in Europe, as given by the author [13] shows that the company being very large adopted EDI with its own Fordnet software to run on IBM machines with Fordnet training courses. The paper transaction was totally eliminated. This made small companies very difficult to end into Ford's network. Thus the cost of complementing EDI, training to the staff to use it is a costly affair for small firms. Hence the reluctance.

The problem for US suppliers and especially the smaller ones is that they have little choice but to accept the will and network solutions of their large clients. Indeed, the small suppliers have had little and overwhelmingly negative experience with this type of application. This one sided deployment of EDI applications has effectively shut the weaker players [13]. There is a catch phrase 'EDI or die'- meaning that trading partners are required to use the system or customer will not trade with them at all.

The growth of Internet has presented supply chains with many significant opportunities for cost reduction and service improvements. The study has revealed that the use of Internet in supply chain management is rapidly increasing. The key ingredient for success in managing a supply chain is fast, accurate information from wide range of operating areas including transportation, inventory, purchasing, customer service, production scheduling, order processing and vendor operations. The ability to react quickly to market changes and to adjust inventory, production and transportation systems accordingly is necessary for cost reduction and for improved utilization of assets. The Internet has and will continue to provide logistic managers with this information and enable them to improve the profitability of their supply chains. The Internet will 
enable companies to achieve the true efficiencies embodied in supply chain cost reductions. Based on the literature survey six research hypotheses are developed. These hypotheses will be subjected to testing in the next phase of research.

\section{REFERENCES}

[1] Sunil Chopra, Peter Meindl, Pearson Education Pvt.Ltd, Delhi.

[2] Larson, P.D. and J.D. Kulchitsky, Logistics Improvement Programs: The Dynamics Between People and Performance, International Journal of Physical Distribution and Logistic Management, (29:2), 1999, 88-102

[3] Mercussen, C.H., The Effects of EDI on Industrial Buyer-Seller Relationships; A Network Perspective, International Journal of Purchase and Material Management, (32:3), Summer 1996, 20-26

[4] Buhse, T.R., High Tech Contact, Purchasing Today, (8:1), January 1997, 4

[5] Paul, D.Larson, Jack, D.Kulchitsky, The Use and Impact of Communication Media in Purchasing and Supply Chain Management, Journal of Supply Chain Management, Summer 2000, 29-39

[6] Khoo, L. , S.B.Tor, and S.S. G,Lee, Potential of Intelligent Software Agents in the World Wide Web in Automotive Part Procurement, International Journal of Purchase and Material Management, (34:1), 1998, 46-52

[7] Avery, S., Automating RFPs, RIDs Process for Non-value Added Entities, Purchasing, July 16, 1998, 202

[8] Langel, and R.L.Daft, Selection of Communication Media as an Executive Skill, The Academy of Management, $1998,(2: 3), 225-232$

[9] Lee H.L. and Whang.S, Information sharing in supply chain, International Journal of Technology, Management, 2000, 20(3/4), 373-387

[10] C.W. Craighead, J.W. Patterson, P.L. Roth and A.H. Segars, Enabling the Benefits of Supply Chain Management Systems: An Empirical Study of EDI in Manufacturing, 2006, International Journal of Production Research, vol. 44, $135-157$

[11] Zillur Rahaman, Internet Based Supply Chain Management: Using Internet to Revolutionize Your Business, International Journal of Information Management, 23, 2003, 493-505.

[12] Richards Lancioni, Hope Jensen Schan, Mchael F. Smith, Internet Impacts on Supply Chain Management, Industrial Marketing Management, 32, 2003, 173-175

[13] Juliet Webster, Networks of Collaboration or Conflict? , EDI and Power in the Supply Chain, Journal of Strategic Information Systems, 1995, 4(1), 31-42.

[14] Handfield, R.B., S.V. Walton, A.S. Marucheck andA.M. Nilkins, International Purchasing Transactions Through EDI Systems, Inc. Deans and K. Karwan (Eds), Global Information Technology Applications: Focus on the Organization and its Functional Areas, Idea Group Publishing London, 1994

[15] Carter,Jr and G.L. Ragatz, Supplier Barcodes: Closing the EDI Loops, International Journal of Purchasing and Materials Management (27:3), summer 1991,19-23

[16] Porter, A.M., Automation Fails to Free Purchasing from Transactions, Purchasing, October 8, 1998, $20-21$.

[17] Barringer, B.R., The Effects of Relational Channel Exchange on the Small Firm: A conceptual Framework, Journal of Small Business Management, (35:2), 1997, 65-79

[18] Miles, G.Prucee and M.C.Dactz, Dangers of Dependence: The Impact of Strategic Alliance Used by Small Technology Based Firms, Journal of Small Business Management, (37:2), 1999, 20-29

[19] Tulip, S., SME Shun Supply Chain Integration, Supply Management, June 2000, 10

[20] Jairam, J.and S.K. Vickery, Supply Based Strategies, Human Resource Initiatives, Procurement Lead-time, and Firm Performance, International Journal of Purchase and Material Management (34:1), Winter, 1998, 12-23

[21] Emmethenz, M.A, Electronic Data Interchange: Does it Change the Purchasing Process, Journal of Purchasing and Material Management, Winter, 1987, 2-8

[22] Lender, M.R. and Fearson, H.E., Purchasing and Supply Management, $11^{\text {th }}$ Edition, Irwin, Chicago, 1997

[23] Sriram, V. and S. Banergji, Electronic Data Interchange, Does its Adoption Change Purchasing Process and Procedures? , International Journal of Purchase and Material Management, (30:1), Winter, 1994, 31-40

[24] Sebestian, J. Garcia, Dastugue, Douglas M. Lambert: Internet Enabled Coordination in Supply Chain, Indian Marketing Management, 32, 2003, 251-263.

[25] 25. Morgan, J P, New Solutions to Make EDI really work in Purchasing, Purchasing, October 5,2000, pp 42-

[26] Grossman, M., The Role of Trust and the Collaboration in the Internet Enabled Supply Chains, Journal of American Academy of Business, (5: 1/2), 2004, 395-396 